\title{
GENERALIZED NEUROFIBROMATOSIS (Von RECKLINGHAUSEN'S DISEASE)
}

\begin{abstract}
REPORT OF A CASE SHOWING A SUPERFICIAL
\end{abstract} RESEMBLANCE TO HODGKIN'S DISEASE

\author{
CHARLES A. ELLIOTT, M.D. \\ AND \\ ARTHUR F. BEIFELD, M.D. \\ CHICAGO
}

Generalized neurofibromatosis, von Recklinghausen's disease, is by no means a rare condition, occurring in the proportion of about $1: 1,300$ dermatologic cases ${ }^{1}$ ( 85 in 112,775). Were one to take into account the formes frustes of Thibièrge ${ }^{2}$ - cases exhibiting only generalized pigment spots, and a functional, psychic or trophic disturbance, but no cutaneous or nervetumors - the percentage would then be considerably higher.

As the etiology and pathogenesis of the condition are by no means res cdjudicatae, each case not fully conforming to the recognized types merits recording, both for satistical purposes and with a view of throwing new light on some of the obscure features.

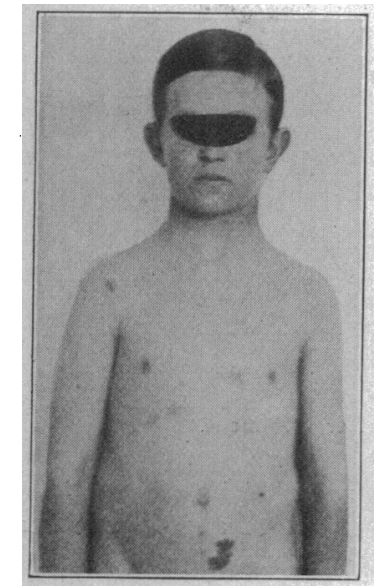

Fig. 1. - Photograph showing lymphatic appearance, cervical swelling, diffuse pigment spots and vated skin tumors.

From time to time, extensive monographs on the subject have appeared. The first, that of von Recklinghausen $^{3}$ (1882), collects the authentic cases recorded up to that year and establishes the condition on a firm clinical and pathologic basis; from his work, the morbid process has derived its name. Alexis Thomson, ${ }^{4}$ in a monograph appearing in 1900 , gave the subject exhaustive treatment. Adrian ${ }^{5}$ (1903), on the basis of 447 cases which he was able to gather from the literature, published a comprehensive review of all features of the process, essential and occasional. So complete is his Sammel-Referate, that a survey of the literature of the last decade-comprising several hundred cases, the majority from French sources--

1. Heidingsfeld: Am. Jour. Dermat., July, 1900.

2. Thibièrge: Société médicale des hôpitaux de Paris, Feb. 18, 1898 ; quoted by Lion and Gasne: Bull. et mém. Soc. méd. d. hôp. de Paris, 1904, xxi, 5.

3. Von Recklinghausen: Ueber die muitiplen Fibrome der Haut, etc., Terlin, 1882, (literature). 1900.

4. Thomson, Alexis: Neurofibroma and Neurofibromatosis, Edinburgl,

э. Adrian: Centralbl. f. d. Grenzgeb. d. Med. u. Chir., 1903, vi, (literature). enables one to add little that is vital to the knowledge of the subject. ${ }^{8}$

The particular interest attaching to the case we wish to record is its superficial resemblance to morbus hodgkinii. At the conclusion of our report, on the basis of our observations and of manifestations recorded in the literature, we desire to emphasize certain items relative to the etiology and pathologic place of the entity.

History.-Master John D., aged 16, a schoolboy, entered Wesley Hospital, April 28, 1914. As was facetiously remarked at the time, he arrived with a written diagnosis in one hand and a vial of vaccine in the other. It would seem that a short time previous to admission he had been under observation at the experimental station of a well-known pharmaceutical house, where he was placed on vaccine treatment for Hodgkin's disease. The diagnosis was made after removal of a subcutaneous node from the right deltoid region; from this tumor, we presume, was cultivated the organism used in the making of the vaccine. As no improvement followed the injections, the boy was referred by $\mathrm{Dr}$. Hayman for observation.

Up to the onset of his present illness, the boy had always been well, except for an attack of measles, two years before. This had affected his eyes and had necessitated his remaining out of school a year.

The family history is irrelevant; there has been no similar illness among his relatives, according to the statement of the boy's mother. There is no history of tuberculosis.?

The present complaint began five to six years ago when there were first noticed scme "lumps" in both cervical regions, though attaining a greater size in the left. These tumors were sensitive to pressure and gradually grew larger, the mass on the left side reaching half the size of his fist. After the lapse of six months, the tumors became smaller and less sensitive. (Particular questioning elicited the fact that when a baby he had "rheumatism," at which time his feet were very tender and he could not walk.)

Soon after the appearance of the cervical masses, the boy noticed tender areas in both arms, which were sensitive following slight bruises; even moving the arms in certain directions caused pain. Somewhat later, small tumors could be felt under the skin of the arms. Subsequently similar tender lumps appeared on the trunk, scalp and lower extremities.

In March of this year the patient discovered innumerable small nodules when passing his hand over the integument, particularly of the arms. In the past year, occipital headache, of frequent occurrence, associated with dizziness has been present.

Present Status (April 4, 1914).-The boy is a well-nourished, healthy appearing lad of 16 , weighing 102 pounds (Figs. 1 and 2). Physically and mentally he seems to represent his years. Aside from nostalgia and worry over the failure of therapy in his case, he feels very well. His appetite is good, he sleeps well, and his bowels are regular. He cannot play, however, as do his friends, because of pain in the groins and popliteal spaces when he romps about. Sudden or extreme movements of the arms also cause pain.

He presents to a certain degree that typical, but difficult to describe, lymphatic facial appearance-a slight puffiness of the lids and skin of the face-which the Germans so happily express as pastös. The teeth are in good condition except for the right lower molar (roentgenogram by Dr. Hollis E. Potter shows no periapical abscess). The gums are spongy and bleed easily; on pressure, pus exudes from the incisors of the lower jaw. The soft palate shows an irregular lymphatic thickening; the tonsils are medium-sized and not distinctly abnormal.

Th right ear has been numb, following the recent (January, 1914) removal (elsewhere) of three small tumors from the right side of the neck. The paresthesia extends also to

6. Kerr: Surg., Gynec. and Obst., January, 1914 (extensive bibliog raphy compiled by Dr. von Klein of the Crerar Library).

7. Wittemann: Med. Klin., 1911, vii, 882 
the right side of the face, neck and shoulders. For a time, the patient could not rest on his side because it felt "boardlike." Another tumor, removed at the same time, from the left cubital region-which was freely movable from side to side, but not from above downward-caused no sensory disturbances. In March of this year, a "lump" was taken from the right shoulder region; from this the diagnosis of Hodgkin's disease was made and the vaccine prepared (!) following which there remained a numbness over the anterior aspect of the right arm.

The most striking feature, from the first glance at the boy, is not the existence of the numerous tumors, but the presence of innumerable diffuse pigment spots of various kinds. The majority of these are freckle-like and distributed chiefly over the trunk; in addition there are seen neviin particular, one large one on the anterior abdominal wall -pea-sized bluish areas surmounting small nodules in the skin, and a patch of atypical hair, redd:sh in hue, the size of the palm of the hand on the left forearm.

The cutaneous and subcutaneous nodes are distributed over the entire body, and vary in size from that of a pinhead to that of a walnut. The largest are in the left cervical region. In the lower cervical region they are massed together like bunches of grapes composed apparently of many hundred tumors on either side. Many of the nodules are associated with a thick firm strand, in most cases coursing centralward from the tumor, in a few peripherally.

An attempt to count the tumors, as a number of writers have painstakingly done, was not made; but it can safely be asserted that they run into the hundreds. No portion of the integument is free from them; a delicate palpation often would reveal a millet-sized node where none was suspected. The large number in the cervical, antecubital, anterior crural and popliteal regions explains the complaint of the boy that moving the arms and legs is painful.

A notable feature of this case is the absence of large skin tumors. The great majority of illustrations accompanying the presentation of these cases show numerous large, sessile, wart-like growths of the skin; in this patient, however, a cursory glance would scarcely reveal an elevated node. Many of the cutaneous lumps are covered with a bluish and bluish-red skin. None gives spontaneous pain, but nearly all are tender to pressure.

As to the remainder of the examination, a few words will suffice. Nodes can be palpated at all the various points where superficial lymph-nodes are ordinarily to be felt. We have assumed (though without the actual removal and examination of any of these nodes) that we have to do with a generalized lymphadenitis, and this assumption has further justification in the percussion enlargement of the spleen-from the sixth rib to two fingers below the costal arch-though a definite edge cannot be felt. The significance of these findings will be commented on later.

The organs of the thoracic cavity show several variations from the normal; dulness over the upper sternum and overlapping the margins, particularly to the left (Figs. 3 and 4 ); and an apex beat and left cardiac border $1 \mathrm{~cm}$. outside the mammillary line with some accentuation of the pulmonic second tone. There are no murmurs. The liver edge is to be felt two fingers' breadth below the costal arch, on deep inspiration, with a smooth surface and sharp edge; on percussion it is not enlarged to the left.

The secondary sexual characteristics are just appearing. Neither testicle is in the scrotum, but they can be pushed down, with little difficulty; the testicles and penis are perhaps small for the age. The reflexes are all present and normal. There is no ankle edema. Examination of the blood (Wittemann ${ }^{\tau}$ ) shows: erythrocytes, 5,240,000, hemoglobin, 85 , leukocytes, 9,400 , distributed as follows: polynuclear neutrophils, 65.5 per cent., lymphocytes, 27.0 per cent., large mononuclears and transitionals 5.0 per cent., eosinophils, 2.0 per cent. and basophils, 0.5 per cent. Practically 90 per cent. of the neutrophils would fall into Classes II and III of Arneth's classification (Dr. Holmes). The Wassermann reaction (blood) is negative (Holmes). The systolic blood pressure is $90 \mathrm{~mm}$.
May 2, a cutaneous tumor (chest wall), a deep tumor (left forearm) the tonsils and the carious molar tooth were removed by Dr. Kanavel. The tonsils were the seat of a chronic inflammation with ulceration (Dr. Zeit). The removal of the node from the forearm furnished a surprise. Before the incision, it was felt as a walnut-sized round tumor, but at operation there was found an egg-sized mass in a fine capsule, composed of several lobes and looking much like a combined fatty and myxomatous tumor of a jelly-like consistency. A careful dissection as to anatomic relations was not made, so that the association of the mass to adjacent nerves was not noted; immediately following the operation, however, partial wrist drop occurred with inability fully to extend the little finger.

Somewhat later there was removed from the left scapular region a tumor made up of convolutions of interwoven strands studded here and there with nodules (plexiform neuroma ; Rankenneurom).

Microscopically (hematoxylin and eosin [Fig. 5]), the excised tumors showed the picture characteristic of von Recklinghausen's disease-a spongy, myxoma-like tissue with many meshes and without definite structure. Some of the spaces are lined with endothelial cells, but the bulk are formed by protoplasma-poor cells, all of about one size. With this stain the plasma-cells emphasized by Unna ${ }^{8}$ are not seen. The Marchi method (Fig. 6) shows bundles of apparently normal axons in the tumor mass (Dr. Ranson).

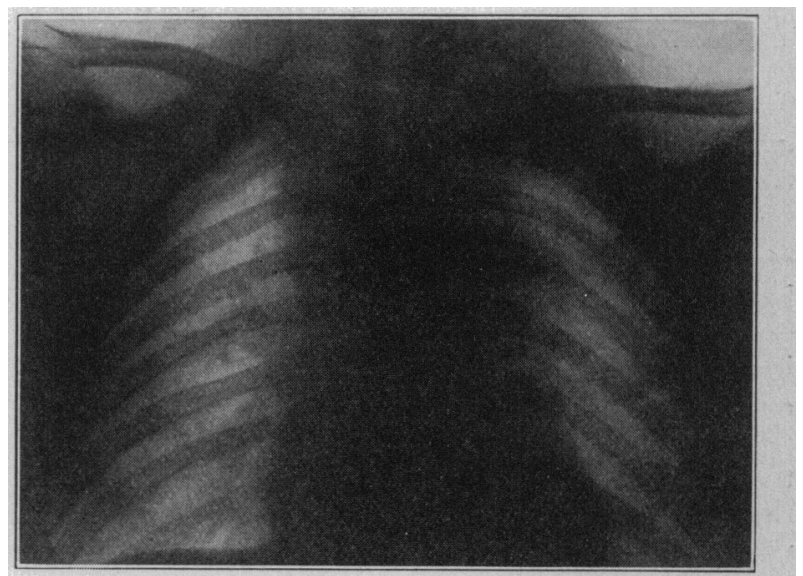
Fig.

Fig. 3.-Chest, anteroposterior, showing mediastinal mass capping the

That we have to do with a case of neurotibromatosis is clear from the clinical manifestations, surgical sequelae and microscopic examination. The symptoms of the first order (Adrian) are all present, that is, tumors of the skin, tumors of the nerves and cutaneous pigment anomalies. Of the symptoms of the second order, so called-functional disturbances, intellectual and psychic changes, maldevelopment of various kinds, bone changes and the like-there is but little to be seen; and, indeed, in the majority of reported cases they are usually absent or only suggested. The headache and dizziness belong to the group of functional disturbances so far as we have been able to determine, for there is no evidence of an intracranial neurofibroma.

Of intellectual and pyschic anomalies there is no sign. The boy seems normal except for the lymphatic appearance already commented on.

In the category of developmental faults belongs the condition of cryptorchism. Bone changes not infrequently observed, scoliosis particularly, are absent; and there are no trophic disturbances.

\footnotetext{
8. Unna: Fibrome, Histopathologie.
} 
Our patient exhibits, in brief, few findings which have not frcquently been commented on by other observers. One unusual feature is the non-critical resemblance to Hodgkin's disease-the appearance of the first nodes in the cervical region, their initial enlargement, the generalized lymphadenopathy, the enlarged spleen, etc. For these we shall offer below a different interpretation. As for the organism cultivated from one of the nodes, we can offer no explanation save that it may bear some relation to bacterial

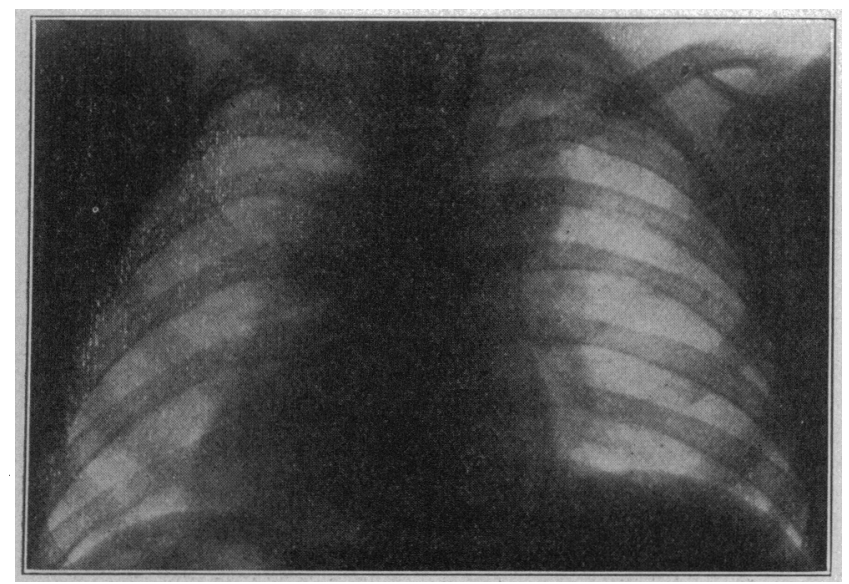

Fig. 4.-Chest, postero-anterior, showing same as Figure 3.

flora not uncommonly present in new growths. Cultures in our laboratory were sterile (Holmes).

The absence of large cutaneous tumors growing considerably about the skin level may be accounted for by the age of the process; they may be looked for later, or perhaps this is one of the forms which tends to involve the deeper nerve filaments rather than the cutaneous.

There is no congenital, hereditary or familial aspect to this case- a feature so striking in many observations. The patient falls into that rather large class which shows no evidence at birth of the coming condition and begins to develop it at puberty.

As to nomenclature, many observers, notably von Recklinghausen, ${ }^{3}$ Adrian ${ }^{5}$ and Orth, ${ }^{9}$ have taken exception to the name neurofibromatosis as representing incorrectly the nature of the growth. That the growths are not essentially of nervous origin is well known; that they arise frcm the neurilemma sheaths or from the fibrous investment of certain cutaneous appendages or subcutis or perhaps from both structures, is generally accepted. ${ }^{10}$ Their origin from an embryonic nervous tissue has been advocated in late years. ${ }^{11}$ Hence the name neurofibromatosis is not apt in that it attributes to nervous tissue proper a false participation in the process. False neuroma is no improvement. Adrian's suggestion of the term "von Recklinghausen's disease" seems to him the best and least open to adverse criticism. French observers generally employ this term.

There remains now the consideration of the many theories put forth from time as to the actual nature of von Recklingh-usen's disease. Adrian reviews the ideas held up to the year 1903. All observers who have expressed an opinion on the point are agreed that

9. Orth: Deutsch. med. Wchnschr., 1911, p. 473

10. Jarisch: Hautkrankheiten, Wien' und Leipzic, 1908, p. 810 (literature of this phase). Footnote 12). it is a disease which comes into being through some general impetus; it is a system disease affecting a particular tissue (Verocay ${ }^{12}$ ). The infectious, the toxic, the traumatic and the sympathetic influence theories are to-day no longer generally put forth, though Pic and Gauthier ${ }^{13}$ in 1907 point out the close association of the condition with tuberculosis. We shall refer later to the view of Chauffard and others that the adrenals are affected.

The view most generally advocated and the one best founded is that the condition arises on an inborn tendency-an anlage-which exerts its influence at variable times after birth and leads to the proliferation of the fibrous tissue making up the neurilemma sheaths.

It is our opinion, however, based on certain peculiarities of the case we have reported, on features of cases we have collected from the literature, and on general considerations, that von Recklinghausen's disease belongs to the larger congenital anomaly known as the status thymicolymphaticus sive hypoplasticus. Space forbids our entering in any detail, into the complexities of this condition, to which so much attention has been devoted of recent years. ${ }^{14}$ Speaking for the condition in our case are the peculiar lymphatic facies, the hypertrophic faucial lymphatic ring, the generalized lymphadenopathy, the enlarged spleen, the persistent and enlarged thymus, the scanty axillary and pubic hair, the cryptorchism, the small testicles and penis, and the very tendency toward tumor formation -particularly multiple. All of these go to make up the thymicolymphatic and hypoplastic status, or condition of structural inferiority (Minderwärtigkeit).

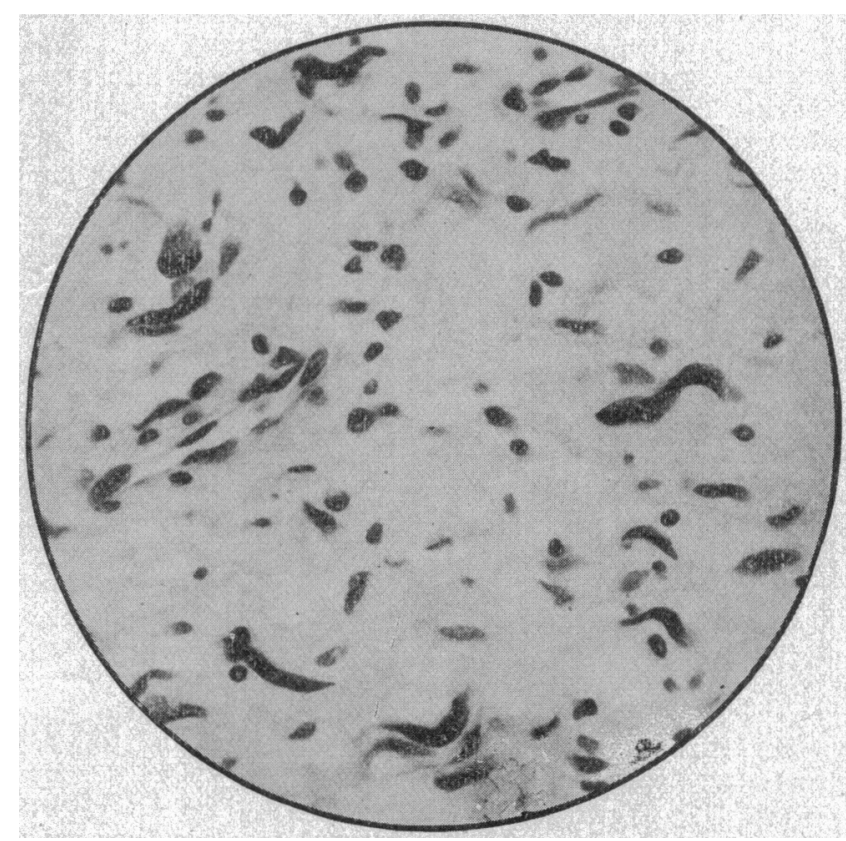

Fig. 5--Microscopic section of tumor removed from the left forearm, hematoxylin-eosin stain, $X 450$, showing loosely interwoven texture,
marked edema of stroma and cells made up almost entirely of nuclei.

Other observers have not noted this association of the lymphatic status with von Recklinghausen's discase. We have been able, however, to collect from this case or that, one or more recognized attributes of the

12. Verocay: Beitr. z. path. Anat. u. z. allg. Path., 1910, xlviii, 1 13. Pic and Gauthier: Lyon méd., 1908, cxl, 1148. 14. Bartel: Status Thymico-Lymphaticus und Status Hypoplasticus, Wien, 1911. Von Neusser: Ausgewählte Kapitel d. klin. Symptoma-
tologie und Diagnostik H. 4. Zur Diagnose der Status Thymico-Lymphatologie und Diagnostik H. 4. Zur Diagnose der Status Thymico-Lymphaticus, Wien, 1911. Wiesel, Status Thymico-Lymphaticus, in Lew
dowsky: Handbuch d. Neurologie, Berlin, 1913, p. 380 (literature). 
association of the two conditions, as do Bourcy and

anomaly. Sabrazés ${ }^{15}$ notes the generalized lymphadenopathy, Klinger ${ }^{16}$ the absence of pubic hair. Wittemann $^{7}$ in his cases observed a mononucleosis regularly. In Ehrmann's ${ }^{17}$ case the hands of the patient reached almost to his knees-a disproportion frequently observed in the status lymphaticus. Various malformations are generally looked on as one of the symptoms of the second order belonging to von Recklinghausen's disease. For a compilation of these, we would refer the reader to Adrian's monograph. ${ }^{18}$

Very striking in a number of case histories has been the early and unexplained lethal ending after operation on large tumors which offered no technical difficulty. Among such records are cases reported by Piollet, ${ }^{19}$ Lambret and Gérard, ${ }^{20}$ and Littlewood, Telling and Scott. ${ }^{21}$ Though these are not strictly instances of thymic death, they are to be ascribed in all probability to a lack of resistance.

It would appear to us, therefore, that closer examination, in the future, directed particularly to evidence of the presence of stigmata of the status thymicolymphaticus, would furnish convincing proof of the association of the two conditions.

Another phase of von Recklinghausen's disease which has been cursorily treated in the last decade, particularly by French writers, is the influence of the glands of internal secretion in the process. Again we refer to Adrian for assembled instances, up to the year 1903, of involvement of the ductless glands and for symptoms referable thereto. Chauffard and Ramond ${ }^{22}$ in 1896 advocated the adrenal theory of the origin of the disease, basing their opinion on the generalized pigmentation, the commonly observed asthenia, gastro-intestinal disturbances and other evidences of adrenal insufficiency. In two of their cases coming to necropsy adrenal changes were discovered, in one an adenoma, in the other atrophy. The adrenal theory, though never of general acceptance, has received a great deal of consideration by many observers.

The majority felt that the association was merely a coincidence. (We would call attention, however, to a recognized pathologic fact, namely, that Addison's disease is almost constantly accompanied by stigmata of the status lymphaticus.) Adrian ${ }^{5}$ rejects the adrenal theory, citing the various observations bearing on the relationship. $\mathrm{Merk}^{23}$ in his case found changes in the left adrenal and cannot entirely disregard Chauffard's view. The chromaffin system was found hyperplastic in Orzechowski's ${ }^{24}$ patient. Gabriel ${ }^{25}$ and others have observed good results from the use of adrenal extract. Vignolo-Lutati ${ }^{26}$ observed a well-developed Addison complex in his case. Revil$\operatorname{lod}^{27}$ and $\mathrm{Pic}$ and Rebattu ${ }^{28}$ comment on the frequent

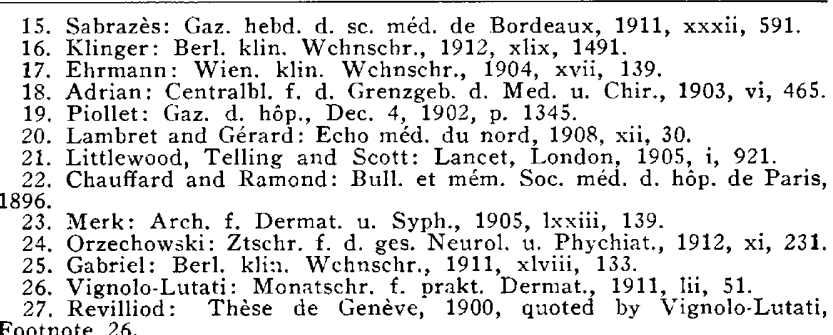

Laignel-Lavastine. ${ }^{29}$ Mucous membrane pigmentation was noted by Oddo. ${ }^{30}$

Thyroid disturbances are also of frequent occurrence. Adrian has gathered several instances of the association of von Recklinghausen's disease and cretinism. $^{31}$ Pic and Rebattu ${ }^{28}$ found thyroid changes. In one of his cases Ehrmann found a small thyroid, in the other an absence of the gland. It is interesting to note that joint changes are not infrequently present in disturbances of the ductless glands. Preble and Hektoen $^{32}$ report a case of von Recklinghausen's disease associated with arthritis deformans. And, furthermore in the latter condition, thyroid extract has been used with favorable results (Midelton, ${ }^{33}$. Llewellyn ${ }^{34}$ ). It is scarcely necessary to recall here the close rela tionship of thyroid, sexual glands and thymus. ${ }^{35}$

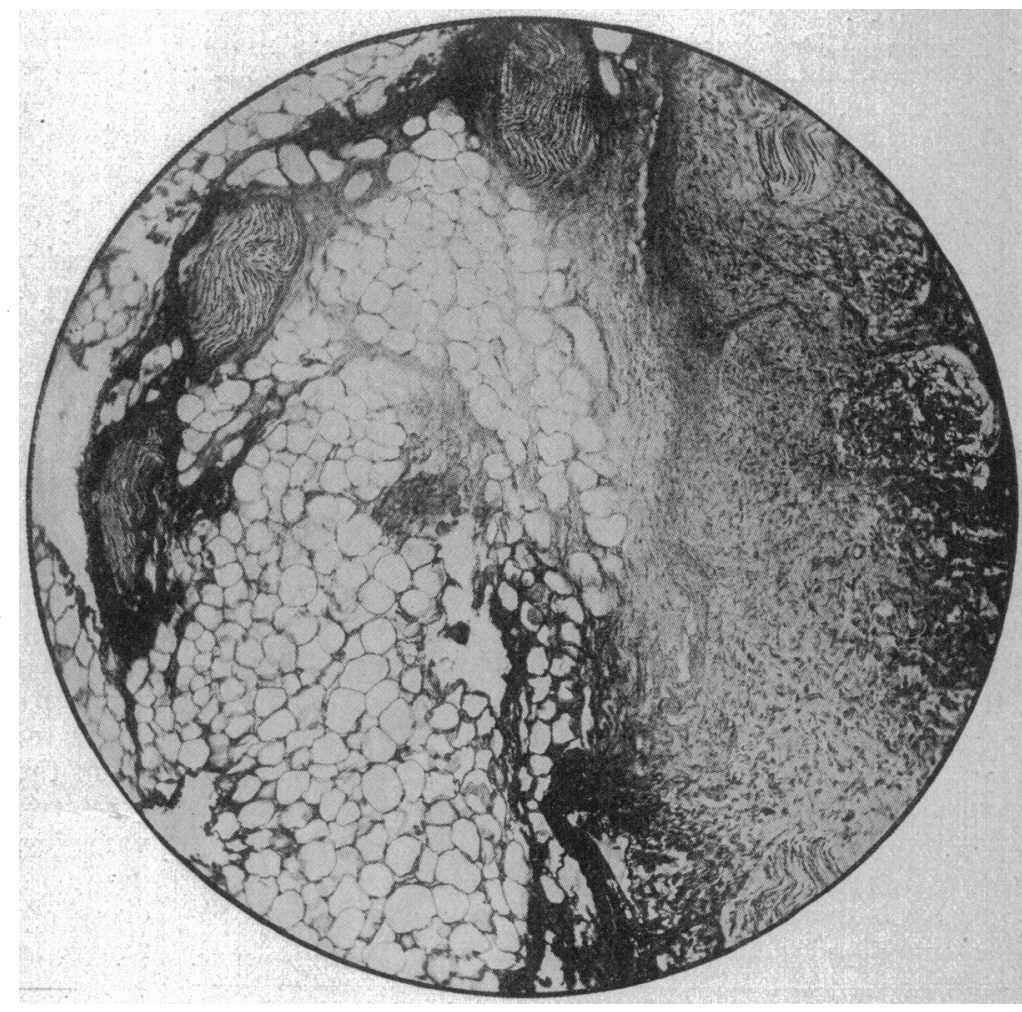

Fig. 6.-Microscopic section of plexiform neuroma (see text) stained by March nethod, showing bundles of nerve fibers loosely separated by edematous tumo stroma; $\times 60$
Of the behavior of the thymus we have found no record. Functional sexual disturbances-impotence, frigidity, diminished libido-are noted by Adrian. Orzechowski ${ }^{24}$ found ovaries below par. Meige and Feindell ${ }^{36}$ note ovarian disturbances. Osteomalacia is very frequently observed, as for example by Gabriel, ${ }^{25}$ Klinger, ${ }^{37}$ Wechselmann ${ }^{38}$ Marie and Couvelaire ${ }^{39}$ and Hoisnard. ${ }^{39}$ Menstrual anomalies are of frequent record (Adrian)

\footnotetext{
28. Pic and Rebattu: Lyon méd., 1907, i, 636.

29. Bourcy and Laignel-Lavastine: Bull. et mém. Soc. méd. d. hôp. de Paris, 1905.

30. Oddo: Revue neurol., 1905, xiii, 412

31. Strohmeyer (1844) and Schuh $(1851,1854)$, quoted by Adrian (Fcotnote 5), p. 461.

32. Preble and Hektoen: Am. Jour. Med. Sc., 1901, cxxi, 1.

33. Micelton: Practitioner, lxxxviii, 11, 80.

35. Lampé: Deutsch. med. Wchnschr., 1912, p. 1127, Capelle: Beitr.

z. klin. Chir., 1908, lviii, 35

36. Meige and Feindell: Revue neurol.. 1903, p. 157

37. Klinger: Berl. klin. Wchnschr., 1912, xlviii, 1400

38. Wechselmann: Dermat. Stud., 1910, $\mathrm{xx}, 133$

39. Cited by Adrian (1 ootnote 5 ).
} 
Schlesinger ${ }^{40}$ in his case found an associated tetany. This is the only recorded instance of parathyroid involvement. We have found no reference to pancreas changes except for a normal organ in Orzechowski's ${ }^{24}$ case.

Numerous observers record the simultaneous involvement of the hypophysis. Prognathism without further comment is a common observance. Acromegaly and von Recklinghausen's disease are chronicled by De Castro, ${ }^{41}$ Wolfsohn and Marcus, ${ }^{42}$ Cushing, ${ }^{43}$ Nicholas and Favre ${ }^{44}$ and others. Thomas ${ }^{43}$ observed fingers and lower jaw suggestive of acromegaly; Feindel and Frounard, ${ }^{46}$ an acromegalic skull contour. A tumor of the sella turcica was present in Spillman's ${ }^{46}$ case; in Mossé and Cavalie's ${ }^{46}$ an enlarged and hard hypophysis was found. Piollet ${ }^{19}$ records pituitary insufficiency and also acromegalic facies and extremities.

That von Recklinghausen's disease may be a manifestation of pluriglandular disturbances has been noted by several writers, notably $\mathrm{Pic}$ and Rebattu, ${ }^{28}$ Orzechowski ${ }^{24}$ and De Castro. ${ }^{41}$ Their deductions have been based, however, on symptoms shown by their own cases; no observer, to our knowledge has heretofore collected extensive data from the literature showing the not uncommon occurrence of ductless gland disturbances in generalized neurofibromatosis.

Direct proof that von Recklinghausen's disease is part of the larger congenital anomaly known as the status thymicolymphaticus, or that the secretions of the ductless glands play a part in its production, cannot of course be adduced. The close interweaving of the lymphatic status and ductless gland affairs is well known; and considerable evidence is at hand to indicate that von Recklinghausen's disease is a manifestation of both. This is particularly understandable if one admits the embryonic nature of the tissue forming the tumors.

Note: Dercum's disease, adipositas dolorosa, has received considerable attention of late as an internal secretion disorder. In its tendency toward multiple tumor formation it resembles von Recklinghausen's disease. It is of interest to note that in the latter, lipomas are of frequent occurrence. ${ }^{47}$

30 North Michigan Avenue-122 South Michigan Avenue.

40. Schlesinger: Mitt. d. Gesellsch. f. inn. Med. u. Kinderh., in Wien, $1911, x, 124$.

41. De Castro: N. iconog. de la Salpêtrière, 1912, xxy, 41

42. Wolfsohn and Marcus: Berl. klin. Wehnschr., 1912, xlix, 1088.

43. Cushing: The Pituitary Body and its Disorders, Philadelphia, 1912 , p. 148 .

44. Nicholas and Favre: Lyon méd., 1910, cxiv 786

45. Thomas: Bull. Jol.ns Hopkins Hosp., 1903, xiv, 204; also Maryland

Med. Jour., 1903, xlvi, 82.

46. Ciied by Wolfsohn and Marcus (Footnote 42).

47. Cushing (Footnote 43): Von Stejskal, Mitt. d. Gesellsch. f. inn. Med. u. Kinderh., 1907, vi, 153 .

Vis Medicatrix Naturae.-One of the most interesting facts in regard to the regenerative capacity-Nature's power of healing-is its adaptive distribution. It tends to occur in those animals and in those parts of animals which, in the natural conditions of their life, are particularly liabie to non-fatal injury. Long-legged and lanky animals like crabs and star-fishes usually show much of it; a self-contained globular animal like a sea-urchin shows little. The chameleon is one of the few lizards which cannot regrow its tail, for it keeps it safely coiled around the branch. Another very interesting fact is that what is regrown is not always quite true to pattern-the crab does not always get an eye for an eye, but it may be an antenna for an eye. The lizard does not always regrow its own tail, but its grandfather's, so to speak.-J. Arthur Thomson, Brit. Mcd. Jour.

\section{SPONTANEOUS SUBARACHNOID HEMORRHAGE}

\section{A CONTRIBUtion TO THE SUBJECT OF MENINGEAL HEMORRHAGE*}

SAMUEL LEOPOLD, M.D.

Instructor in Neurology and Neuropathology, University of Pennsylvania

PHILADELPHIA

Aside from the rare pachymeningitis hemorrhagica interna, and the traumatic pial hemorrhage, there has been no recognition of a spontaneous subarachnoid hemorrhage. Although this symptom-complex has been elaborately studied by Froin, ${ }^{1}$ Chauffard, ${ }^{2}$ Vigneras $^{3}$ and others among the French writers, little or nothing is mentioned of the subject by the American, English or German writers, Starr, Dana, Mills, Oppenheim, Finkelburg in Lewandowsky's ${ }^{4}$ handbook, Schultze in Nothnagel's "System," and others.

In describing meningeal hemorrhage, Gowers does not differentiate the subarachnoid from the other forms, but his description corresponds very closely to this type. He says :

Blood may be extravasated, (1) outside the dura, separating it from the bone; (2) beneath the dura; (3) beneath the arachnoid between it and the pia (subarachnoid hemorrhage). - . Meningeal hemorrhage occurs apart from visible aneurysm under the same conditions as hemorrhage elsewhere in the brain. . . . In some cases in young adults, the occurrence of meningeal hemorrhage is probably indicated by intense pain in the head at one spot, soon followed by coma and convulsions. The cases are remarkable as occurring without other exciting cause than exertion in a hot room. or sometimes after a meal.

Froin, in 1903, collected some reports of cases of subarachnoid hemorrhage but he included the traumatic form among them. Ehrenberg ${ }^{5}$ was the first to separate the spontaneous subarachnoid hemorrhage from the rest. He reports two of his own, and analyzes twenty-seven other cases. He distinguishes two varieties, the one in which the meningitic picture predominates; the other an apoplectic onset, with coma or cerebral type. Since then Babinski ${ }^{\beta}$ and Jumentie report two cases, and Forsheim ${ }^{7}$ one.

Two of my cases illustrate the apoplectic form, and one the meningitic.

CASE 1.-B. Y., white, aged 59, married, was admitted to the hospital April 25, 1910. Present illness began suddenly with vomiting, headache, pain in the epirastrium and stupor. (I had no opportunity of studying this case clinically and the notes taken are very meager.) The pupils were equal. reacted to light and accommodation. There were no paralyses. The patient died the next day. No clinical diagnosis was made.

At necropsy, examination of the brain showed a hemorrhage beneath the arachnoid at the base. It extended forward to the frontal lobes, and surrounded the optic chiasm. It covered the under surface of both the pons and the medulla. It covered the inferior surfaces of both hemispheres of the cerebellum. The convexity of the brain was free from hemorrhage. There was no evidence of meningitis or throm-

* Read before the Section on Nervous and Mental Diseases at the Sixty-Fifth Annual Session of the American Medical Association Atlantic City, N. J., June, 1914

1. Froin: Thèse de Paris, 1904. Froin and Boidin: Gaz, d hôp. 1904 , p. 9 .

2. Chauffard and Boidin: Presse Méd., 1903.

3. Vigneras: Thèse de Paris, 1908.

4. Lewandowsky: Handbuch de Neurologie.

5. Ehrenberg: Hygeia, 1912, p. 849.

6. Babinski: Soc. méd. d. hôp. d. Paris, 1912.

7. Forsheim: Deutsch. Ztschr. f. Nervenh., 1913, slix. 